Paper

\title{
Relevance and meaningfulness: Student perspectives on the highly talented international business professional profile
}

\author{
Petra van Heugten ${ }^{1 *}$, Marjolein Heijne-Penninga ${ }^{2}$, Patricia Robbe ${ }^{3}$, Debbie Jaarsma ${ }^{4}$, and \\ Marca Wolfensberger ${ }^{5}$
}

1 Hanze University of Applied Sciences, the Netherlands;

p.a.m.van.Heugten@pl.hanze.nl

$2 \quad H a n z e$ University of Applied Sciences, the Netherlands; marjolein.thuis@hotmail.com

$3 \quad H a n z e$ University of Applied Sciences, the Netherlands; p.robbe@pl.hanze.nl

$4 \quad$ University of Groningen, the Netherlands; a.d.c.jaarsma@umcg.nl

$5 \quad$ Hanze University of Applied Sciences, the Netherlands;

m.v.c.wolfensberger@pl.hanze.nl

*Correspondence: p.a.m.van.Heugten@pl.hanze.nl

Received: 29 August 2019; Accepted: 21 July 2020; Published: 29 August 2020

\begin{abstract}
Competencies deemed relevant and meaningful by international business professionals and implemented in IB education still do not produce work-ready graduates. This may be because these competencies are not perceived as relevant or meaningful by students. This study was conducted to gain students' perspectives on the relevance and meaningfulness of the HTIBP talent competency framework and how they perceived working with it. Results show that the five competency domains of the HTIBP competency framework are perceived as relevant and meaningful by students, in alignment with the professional field, however, this was not the case for a few associated items (behaviors) like "showing entrepreneurship" and "improving ideas from others." The lack of clarity of these behaviors resulted in less experienced relevance and meaningfulness by students. Our findings will help educators to better facilitate students' understanding the meaning and relevance of competencies. This may help to improve alignment with the professional field.
\end{abstract}

Keywords: talent competencies; business education; student perception; meaningfulness

\section{Introduction}

In a changing and globalized environment, undergraduate international business (IB) education faces challenges to prepare students for high levels of performance to meet the 
needs of the professional field (Jackson, 2013; Tarique and Schuler, 2010). This is attained by developing competencies and other characteristics needed to function and thrive in employment (De Vos, De Hauw, \& Van der Heijden, 2011). In higher education, learning outcomes are therefore often formulated in terms of competencies, a coherent set of knowledge, skills, and abilities (Van Merriënboer et al., 2002). Competencies are presented in frameworks, which are used to design education (Allen, Ramaekers, \& van der Velden, 2005; Boyatzis 2008, Chyung, Stepich, \& Cox, 2006) aiming to prepare students for their working life and career success (Biemans, Nieuwenhuis, Poell, Mulder, \& Wesselink, 2004; Boyatzis, 2008; De Bruijn \& Leeman, 2011). Competency frameworks are also used as a tool for the professional field and higher education to ensure that the interpretation of the competencies is the same between stakeholders (Tran, 2015). Despite much effort to improve alignment between education and the professional field, it is not yet optimal, and the graduates are not always work-ready (Jackson, 2009; McQuaid \& Lindsay, 2005; Osmani, Weerakkody, Hindi, Al-Esmail, Eldabi, Kapoor, \& Irani, 2015; Tran, 2015).

Literature describes possible factors that may contribute to the lack of alignment between education and the professional field of international business. For example, business schools do not always choose to concentrate on the same competencies that businesses do (Abraham \& Karns, 2009). Some competencies may be inadequately addressed, while some may be overrepresented in the curriculum. Another possible contributing factor to a lack of alignment is that the competency frameworks may not be clearly described, and the language used may be confusing (Dragoo \& Barrows, 2016; Jackson, 2014). If competency frameworks are not clearly described, this may cause differing interpretations between educators and the professional field (Jackson, 2014). Therefore, it is important for the professional field and educators to collaborate and align with each other so that the competency frameworks are interpreted and used as intended.

To also improve this alignment, student opinions and interpretations of competency frameworks play an important part. If the competency frameworks are not clearly described, they may be confusing and difficult to work with for students. If students work with the competency framework incorrectly, they may not learn what is intended and what the professional field renders important.

Clarity and relevance of competencies is especially important in a social constructivist view on learning where students themselves construe learning outcomes based on competency frameworks. In this type of education, students are stimulated to use experiences to construe new meaning (Bruner, 1990). In this setting, educators fulfil the role of facilitators or mentors (Schell, 2000). They help students to understand the meaning, relevance and meaningfulness of the competency framework used, and guide students to design their own learning outcomes.

According to Tymon (2013), to ensure alignment between education and the professional field, students need to regard the competencies as relevant and meaningful. However, the research of Dragoo \& Barrows (2016) and Nodine (2016) showed that competency frameworks are often not clear to students. Therefore, the aim of this paper is to research student perspectives on the clarity and relevance of competency frameworks. 
By researching student perspectives on the relevance and meaningfulness of competencies, educators can better facilitate and support students and help them where needed. Educators can support students in formulating their personal learning outcomes in relation to the competencies and improve alignment with the professional field.

\subsection{Relevance and meaningfulness}

When the relevance of competencies is clear and considered essential, the underlying meaning behind the competencies is also clear, and this is mutually inclusive. When students see the competencies as meaningful and relevant, this influences their motivation to understand and work with them (Vansteenkiste et al., 2006).

A theory concerned with motivation is the self-determination theory (SDT), which describes that intrinsic motivation is stimulated when three basic needs are met: relatedness, competence, and autonomy (Ryan \& Deci, 2000). To meet the needs of feeling competent and experiencing autonomy, seeing the relevance of tasks - in this case the competency profile - is important (Ryan \& Deci, 2000). When students understand the relevance and goals of the competencies, they are better able to assess their capabilities, and this can enhance their feelings of competence (Jang, Reeve, \& Deci., 2010). When the need for competence is met, students may feel better equipped to handle more autonomy, to make choices concerning their goals, and to formulate their own learning outcomes.

Competency frameworks can be a guide for students on which to base their learning outcomes, and, therefore, it is important that the relevance of the competencies is clearly communicated to students in order to achieve the learning that is intended (Beck \& Kosnik, 2006; Moeller, Theiler \& Wu, 2012; Mouratidis, Vansteenkiste, Michou, \& Lens, 2013; Reeve, 2009). As students relate relevance and meaningfulness of the competencies to their understanding of the contents of them, it makes clear descriptions of the competencies important (Dragoo and Barrows, 2016; Jang et al, 2010). Especially in the context of being offered freedom and autonomy, interpretation of the competencies by students when formulating learning outcomes may vary and may further enhance the gap between what professionals want graduates to learn and what they actually learn.

\subsection{Honors education}

Honors programs (HPs) provide a setting in which a social constructivist view on learning is advocated. These programs are described as study programs linked to higher education that are designed for students, who are able and willing to do more than the regular program offers (Scager, Akkerman, Keesen, Mainhard, Pilot, \& Wubbels, 2012; Wolfensberger, 2015). Learning outcomes in HPs aim to prepare high performers and have become increasingly popular due to the increasing demand for high performers in the workplace (Wolfensberger, 2015), and this is also the case in international business (Beechler \& Woodward, 2009; Farndale, Scullion, \& Sparrow, 2010; Florida, 2006; Silzer \& Church, 2009; Tarique \& Schuler, 2010).

In the HP in IB, the competencies for high performance have been described in the competency profile for highly talented international business professionals (HTIBP) (van Heugten, Heijne-Penninga, Paans, \& Wolfensberger, 2016), developed in co-operation with the professional field. The HTIBP profile is used to inform the HP of the competencies and the associated behaviors that need to be further developed. HP students use the HTIBP to 
design and formulate their own learning goals, and these are discussed with their mentor. At the end of a learning activity, the HTIBP competency framework is used to check if students have achieved their planned learning outcomes.

Honors students have certain characteristics that differ in a number of areas from regular students. They are typically curious and intrinsically motivated (Scager et al., 2012) and desire more thought-provoking and challenging and complex tasks (Shore \& Kanevsky, 1993). In addition, they have a creative and innovative mindset (Banis-den Hertog, 2016), are "more flexible in their use of strategies, have better memories, know more, and prefer complexity" (Scager, Akkerman, Pilot, \& Wubbels, 2014, p. 659). Honors students do not like courses that are completely structured and organized (Reis \& Renzulli, 2010), and they have a need for autonomy to direct their own learning and formulate their own learning outcomes (Wolfensberger \& Offringa, 2012).

That makes honors programs a very suited context to research students' perspectives on the HTIBP competency profile and whether they perceive the profile as relevant and meaningful in their education.

Therefore, we have formulated the following research question(s):

1. What are the IB honors students' perspectives on the meaningfulness and relevance of the HTIBP competency profile of highly talented international business professionals?

2. How have the IB honors students perceived using the profile in their education?

\section{Methods}

\subsection{Context of the study}

The study was conducted at the Hanze University of Applied Sciences in Groningen, the Netherlands. Students of the honors program (HP), which is part of the undergraduate program in the field of International Business Studies (IBS), participated. This HP is extracurricular, and students receive 30 ECTS credits after completion in addition to the total 240 ECTS credits awarded for the four-year undergraduate program. The HP starts in the first semester of the second year of the IB program and continues through to year four. Talented and motivated students within IBS apply to participate in the program by submitting a written portfolio and attending individual and group interviews. The profile of highly talented international business professionals (HTIBP) (van Heugten et al., 2016) is used as the competency framework (Table 1). 
Table 1. HTIBP profile describing the domains and items (behaviors) of highly talented international business professionals (van Heugten et al., 2016)

\begin{tabular}{|c|c|}
\hline Domains & Items (behaviors) \\
\hline \multirow[t]{3}{*}{ Achieving results } & Showing perseverance in complex environments \\
\hline & Taking responsibility for achieving goals \\
\hline & Showing entrepreneurship \\
\hline \multirow[t]{3}{*}{ Communicating } & $\begin{array}{l}\text { Using language effectively in different cultural } \\
\text { and professional settings }\end{array}$ \\
\hline & $\begin{array}{l}\text { Continuing to ask questions to get a clear } \\
\text { understanding of the situation }\end{array}$ \\
\hline & $\begin{array}{l}\text { Listening actively to identify a problem or an } \\
\text { opportunity }\end{array}$ \\
\hline \multirow[t]{4}{*}{ Innovating } & Coming up with creative ideas proactively \\
\hline & Improving ideas from others \\
\hline & $\begin{array}{l}\text { Keeping up with the latest professional } \\
\text { developments }\end{array}$ \\
\hline & $\begin{array}{l}\text { Showing inventive, new possibilities by thinking } \\
\text { 'out of the box' }\end{array}$ \\
\hline \multirow[t]{3}{*}{$\begin{array}{l}\text { Seeing patterns and interrelationships } \\
\text { in a global context }\end{array}$} & $\begin{array}{l}\text { Adapting one's professional approach to another } \\
\text { culture }\end{array}$ \\
\hline & Combining expertise from different specialties \\
\hline & $\begin{array}{l}\text { Showing patience and control in culturally diverse } \\
\text { environments }\end{array}$ \\
\hline \multirow[t]{3}{*}{ Self-reflecting } & $\begin{array}{l}\text { Showing independence in thinking of new } \\
\text { possibilities }\end{array}$ \\
\hline & $\begin{array}{l}\text { Understanding one's strengths and weaknesses, } \\
\text { and acting upon it }\end{array}$ \\
\hline & Improving oneself beneficial to the organization \\
\hline
\end{tabular}

The HTIBP competency profile has been established in collaboration with the professional field and consists of five domains and 16 items or behaviors that characterize excellence (van Heugten et al., 2016). Honors students construe their own learning, using the HTIBP as their reference, and. at the end of their learning journey, the HTIBP is used to inform the final evaluation and assessment. 
At the start of the HP, students are assigned a mentor, who acts as a facilitator to guide students through their learning process and with whom an individual learning plan is discussed. Students choose areas that are specifically beneficial to them personally and professionally and formulate learning goals, which are focused towards the domains of the HTIBP. They will base this selection upon the domains of the HTIBP in which they still need to develop and will discuss this with the mentor who will ensure that the choices are in line with the personal or professional goals. Where applicable, the students' learning goals are discussed with an external professional expert.

Students are encouraged to develop their competencies by taking part in (external) projects and assignments, courses, and activities related directly back to their personal goals and professional development and are free to select one of the five domains of HTIBP to be enhanced by a project, assignment, activity, or course of their own choice. Students and the mentor collaboratively write learning outcomes.

Additionally, there are also some projects, courses, and activities offered in the HP, from which students may select one that best fits their own goals. Students have freedom to choose whether they want to demonstrate their learning orally, by making a presentation, in writing in the form of a written report, or by continual assessment.

\subsection{Participants and procedure}

The IB HP program aims to teach students to become highly talented international business professionals. To gain insight in the students' perspectives on the HTIBP competency framework, we asked them whether the competencies are essential for highly talented business professionals using a survey. Competencies rated as essential are by definition relevant. This survey was conducted among all year two and year four HP students of the IB undergraduate program $(\mathrm{N}=41)$. Students have had some business project and placement experience to have an informed opinion. Students in year three were excluded from the study due to the fact that they were doing a study and work placement abroad and were not active participants in the HP during that time. The survey was administered on paper during the introduction weeks held prior to the start of the academic semesters in September and February of the academic years 2015 and 2016. All data were processed anonymously.

The survey results were further explored by structured interviews to better understand the results from the survey and to add information about IB honors students' perspectives on the meaningfulness and relevance of the HTIBP competency profile of highly talented international business professionals and how they perceived the use of the profile in their education.

The interviews were conducted following a structured interview guide (Appendix A) according to Hennink, Hutter, \& Bailey (2010). All final year undergraduate IB program students who participated in the HP $(\mathrm{N}=12)$ were invited per e-mail to participate in the interview. These students did not participate in the survey. Informed consent was collected prior to the interviews and the researchers ensured that all data records were kept confidential in line with ethical considerations described by Hennink et al. (2010, p. 63). In total, 10 students participated, and the interviews were conducted in June 2016. The main researcher conducted the interviews, as she was not part of the HP faculty and therefore not 
involved in teaching or coaching the targeted students. The interviews lasted between 30 and 40 minutes and were audio recorded, permission for which had been obtained. The interviews were transcribed ad verbatim, and the texts were anonymized to avoid identification of the interviewees (Hennink et al., 2010, p. 63). Students' names have been replaced by letters.

\subsection{Instruments}

\section{Survey}

For the present study, the survey used to establish the HTIBP competency framework was applied (van Heugten et al., 2016). In 2016, this survey was distributed among international business professionals to gauge their level of agreement on whether the domains and the corresponding items are distinguishing for talent. In this study, as we were interested in the student perspectives on the talent profile, the same survey was conducted among honors students. The survey was set up as follows:

In section one of the survey, students were asked to provide demographic information. In section two of the survey, the students' agreement on the 16 items of the HTIBP profile was gauged. Respondents were asked if the items shown represent highly talented international business professionals. This was measured by scale anchors: 'essential,' 'important but not essential,' or 'not necessary' (Lawshe, 1975). The question asked for all items was: "to what extent do you consider the characteristics listed below important in determining the profile of highly talented international business professionals?" This was repeated in a separate question for the domains of the HTIBP profile. The question for the five domains was: "to what extent, in your opinion, do the domains listed below contribute to defining highly talented international business professionals?"

\section{Interview}

We conducted structured interviews with open questions related to understanding the results from the survey and to understanding students' perspectives on the HTIBP.

The interview consisted of four main questions, each subdivided into smaller sub-questions. The first main question enquired about the low scoring items in the survey to understand possible underlying reasons. The questions asked were: "in a student survey, the behavior 'showing entrepreneurship' is, on average, not perceived as essential to talent (and in the professional field it is). What is your opinion on this?" This question was repeated for the item "improving ideas from others." The domain "innovating," while ranked positively, was included in the interview to better understand the view that one of the related behaviors within this domain was perceived as not distinguishing for talent. The question asked was: "in a student survey, the domain 'innovation' is, perceived as essential to talent. What is your opinion on this?"

The second main question was related to gaining insights into students' perspectives on the meaningfulness and relevance of the HTIBP. The questions asked were: "what domains and or behaviors of the HTIBP profile are (the most and the least) meaningful/ significant to you, and could you explain why?"

The third main question was related to assessment. One interview question was dedicated to asking students how the competencies were assessed and whether this method of assessment was meaningful to them. 
The last main interview question was to gauge students' general opinion on using the HTIBP profile in the HP and whether the profile was regarded to be complete or would need to be adapted. The questions were: "how did you perceive working with the profile? Are there any domains or behaviors that are missing from the HTIB profile?"

\section{Data-analysis}

The survey results were analyzed by calculating the content validity ratio (CVR ratio), a method used to gauge agreement among raters regarding how essential a particular item is (Lawshe, 1975). In this study, the degree of agreement on whether the domains and items (behaviors) in the HTIBP profile are perceived as essential to talent is gauged. In accordance with Lawshe (1975), the following formula was used: CVR $=(N e-N / 2) /(N / 2)$. CVR represents content validity ratio, $\mathrm{Ne}$ the number of participants indicating that the item (behavior) or domain is "essential," and $N$ the total number of participants. This formula produces values ranging from +1 to -1 . Values of 0.0 and above are regarded as positive values, whereby a value of 0.0 shows that half of the raters agree that an item or domain is essential and a value of 1.0 shows full consensus (Lawshe, 1975).

The interviews were recorded and transcribed, and the transcripts served as sources of data for content analysis and were subjected to a qualitative deductive analysis.

All transcripts were read and the questions highlighted to identify them throughout the transcripts. Based on the answers to the questions, the results per question were summarized, which was done by two researchers independently. The summarized answers to the questions were compared between the researchers, and possible discrepancies or inconsistencies were carefully discussed and adapted where necessary.

\section{Results}

\subsection{Student perspectives on the HTIBP profile}

On the basis of the survey, we obtained insight into students' perspectives on the HTIBP, and a summary of these results can be found in Table 2 . This is followed by the results from the structured interviews, related to understanding the survey results better and to understand students' perspectives. 
Table 2. Content validity ratio (CVR) honors students

\begin{tabular}{|c|c|c|}
\hline Domains and items (behaviors) & $\begin{array}{c}\text { Judged as } \\
\text { "essential" } \\
\text { by } n-/- \\
\text { honors } \\
\text { students }\end{array}$ & $\begin{array}{l}\text { Ratio } \\
\text { (cvr) }\end{array}$ \\
\hline Domain Achieving results & $30 / 38$ & 0.58 \\
\hline Showing perseverance in complex environments & $25 / 41$ & 0.22 \\
\hline Taking responsibility for achieving goals & $33 / 41$ & 0.61 \\
\hline Showing entrepreneurship & $14 / 41$ & -0.32 \\
\hline Domain Communication & $35 / 38$ & 0.84 \\
\hline $\begin{array}{l}\text { Using language effectively in different cultural and professional } \\
\text { settings }\end{array}$ & $29 / 41$ & 0.41 \\
\hline $\begin{array}{l}\text { Continuing to ask questions to get a clear understanding of the } \\
\text { situation }\end{array}$ & $29 / 41$ & 0.41 \\
\hline Listening actively to identify a problem or an opportunity & $32 / 40$ & 0.60 \\
\hline Domain Innovating & $25 / 38$ & 0.32 \\
\hline Coming up with creative ideas proactively & $22 / 41$ & 0.07 \\
\hline Improving ideas from others & $11 / 41$ & -0.46 \\
\hline Keeping up with the latest professional developments & $24 / 41$ & 0.17 \\
\hline Showing inventive, new possibilities by thinking 'out of the box' & $28 / 41$ & 0.37 \\
\hline Domain Seeing patterns and interrelationships in a global context & $27 / 38$ & 0.42 \\
\hline Adapting one's professional approach to another culture & $35 / 41$ & 0.71 \\
\hline Combining expertise from different specialties & $29 / 41$ & 0.41 \\
\hline Showing patience and control in culturally diverse environments & $35 / 41$ & 0.71 \\
\hline Domain Self-reflecting & $30 / 38$ & 0.58 \\
\hline Showing independence in thinking of new possibilities & $24 / 41$ & 0.17 \\
\hline Understanding one's strengths and weaknesses, and acting upon it & $35 / 41$ & 0.71 \\
\hline Improving oneself beneficial to the organization & $25 / 41$ & 0.22 \\
\hline
\end{tabular}


Students regard the five HTIBP domains as essential, and thus relevant, for highly talented international business professionals (communication CVR 0.84; seeing patterns and interrelationships in a global context CVR 0.42; innovating CVR 0.32; achieving results CVR 0.58; self-reflecting CVR 0.58).

Besides the domains, the associated behaviors belonging to the domains (represented by the items) are mostly regarded as essential. Levels of consensus about the behaviors vary, particularly for the behaviors belonging to the domain self-reflecting, whereby understanding one's strengths and weaknesses has a high CVR (0.71) and showing independence in thinking of new possibilities has a low, albeit positive, CVR (0.17). Two behaviors are not perceived as essential by students which were considered essential by the professional field. These are "improving ideas from others" (CVR -0.46), belonging to the domain innovating, and "showing entrepreneurship" (CVR -0.32), belonging to the domain achieving results. In the interviews, students were asked to give their opinion on the negative survey ratios, and they indicated that the meaning of the behavior "showing entrepreneurship" was unclear to them. They elaborated that if entrepreneurship referred to starting up a new business, it would not be regarded as essential. However, with the meaning of having an entrepreneurial mindset and creating projects and coming up with ideas, then it would be regarded as essential. Students mentioned that they were unsure how the term was intended. The following quote illustrates:

..."what is entrepreneurship? I think it's a very vague word.. . Is entrepreneurship setting up your own business, is entrepreneurship thinking out of the box? ... the word entrepreneurship is so vague and so hard to grip..." (Student $\mathrm{H}$ )

The second negative survey ratio, "improving ideas from others," was regarded as essential by the interviewees, which was not in-line with the survey results. In the interviews, students elaborated that, especially in the field of international management, the ability to spot potentially good ideas and build on them by giving good feedback was seen as distinguishing for talented professionals.

The interview results revealed that the domain self-reflecting was the most meaningful to all students. Students described self-reflecting as a powerful competency for performance analysis and self-improvement. Comments included for example: "It is a nice tool to discover strengths and weaknesses and areas to improve" (Student A). "Through self-reflection you learn to understand better and gain insight in how to judge your own work" (Student B). In addition, students commented that learning to self-reflect did not occur in the regular IB undergraduate program: "It was never emphasized before." (Student A)

In addition to self-reflecting, the other four domains, achieving results, communicating, seeing patterns and interrelationships in a global context, and innovation, were found to be meaningful by the interviewees but less frequently and with certain conditions related to meaning. For example, the domain achieving results was mentioned as meaningful but only in relation to the importance of the journey and not the result themselves. Innovating when equated to being creative and out of the box thinking was meaningful to students but not in relation to product innovation. Some quotes to illustrate are: 
"Because innovating is something like creating, something new right? I have like kind of stronger relationship with creativity" (Student C). "I cannot relate to innovating" (Student E). "innovating is quite vague" (Student I).

\subsection{Using the profile in education}

In general, students experienced working with the HTIBP to be meaningful. It provided direction for how to fill in their desired learning, and having the freedom to do so was particularly stressed as useful. Some quotes to illustrate are:

"In hindsight I think it was really useful because using the profile you were really specific about the goals that you wanted to achieve" (Student A). "it helped me realize what I need to focus on" (Student F). "The thing I really value is the freedom of seeing the goal of any domain in the way you wanted" (Student B).

Also, using the framework again as a reflection tool to see if the learning outcomes had been achieved was mentioned.

Interview results regarding assessment of the competency framework showed that assessments were mostly done by students giving presentations to the rest of the HP students and their mentors at the end of completed projects or at the end of the study semester. They were asked to reflect upon their learning journey. Prior to this, students had set up learning outcomes based on the HTIBP in collaboration with their mentors. Students commented that the feedback on their learning outcomes by their mentor and feedback on their learning journey and the end-of-project- and semester presentations was especially meaningful to them.

"It's sharing experiences and getting feedback on that, on an appropriate level" (Student J). "regarding the seminars we are assessed through a presentation. I think it's a very good thing....you can see other people's learning journey....So, the assessment of self-reflection is done really really well" (Student I).

In addition, students embraced learning that occurred outside of the scope of what was planned and found it to be useful. In that context, it was mentioned that, in the students' perspectives, standard assessment would not work and that working with feedback and reflection was much preferred. The following quote illustrates this viewpoint:

"...putting that in a standard assessment form I think does not work so well. Because it is not about knowledge or skills or even not about competencies. It's about application" (student J).

\section{Discussion}

This study was conducted to gain students' perspectives on the relevance and meaningfulness of the HTIBP competency framework and how they perceived working with it. Results of this study show that the five domains of the HTIBP are regarded as relevant and meaningful, in alignment with the professional field. However, not all behaviors were regarded as meaningful by students. About working with the profile, students experienced it as meaningful, as it was a compass and offered direction to students for how to fill in their desired learning. Connected to this, the freedom to do the former was experienced as particularly meaningful. In addition, students perceived the framework as a meaningful tool to reflect on their learning and to see if the learning outcomes had been achieved.

Although students confirm the relevance of the five HTIBP competencies, they were critical of the relevance and meaningfulness of some behaviors. Cases in point are 
"entrepreneurship" and "innovation." Entrepreneurship was only regarded as meaningful in relation to having a creative and entrepreneurial mindset and not in relation to a business start-up. Students explained that having an entrepreneurial mindset is the underlying skill to help achieve many things, such as a successful business start-up. Entrepreneurship literature shows a development and expansion in the meaning attached to the term. It expanded from idea generation and related business ventures to a broader definition related to behaviors associated with entrepreneurship (Johnson, 2001) and to human capital and the mindset needed to discover opportunities to exploit and develop (Marvel, Davis, \& Sproul, 2016). With the focus on interpretations of entrepreneurship changing, consensus on the term is missing (Johnson, 2001; Zhao, 2005). In education, it is important to develop the right skills in relation to entrepreneurship, and, according to Neck and Green (2011, p. 55) "entrepreneurship is complex, chaotic, and lacks any notion of linearity", also confirmed by a more recent study by Attali and Yemini (2017).

Against this backdrop, and in relation to the results of our study, two things emerge; firstly, the term entrepreneurship is used in the HTIBP framework as a behavior for the domain "achieving results", whereas it seems that the term entrepreneurship itself has behaviors that can be attached to it (Neck and Green, 2011). It may then be better suited as a domain with its own behaviors. This would create the clarity that is currently missing and needed for students to regard it as meaningful. Without full grasp of what the term entails, misunderstandings will occur. Secondly, students' opinion that relevance is attached to the broader meaning of entrepreneurship as a mindset seems to be in line with the development of the term over time, and thus frequent and constant updating of the meaning attached to competencies in competency frameworks is necessary.

A similar interpretation condition for students to regard it as meaningful was attached to "innovating", where students only found it to be meaningful if it referred to creativity and out of the box thinking and not in relation to product innovation only. Students commented that one can be creative without necessarily relating it to new product innovation. Innovating closely ties in with entrepreneurship literature, and both are regarded as mutually inclusive (Veeraraghavan, 2009). Innovation is seen as coming up with something new, and creativity is the underlying multifaceted force that drives innovation and creativity becomes innovation when the idea is put into practice (Veeraraghavan, 2009). According to Lewrick, Omar, Raeside, \& Sailer, (2011) innovation is not necessarily invention but rather means being creative in applying what others have invented. The term innovation also seems to be interpreted and explained differently and, similarly to entrepreneurship, it is a complex term, which needs further details. If differences in interpretations and explanations exist in the professional field itself, it may not be surprising that this is also the case when it filters through in education and also proves to be difficult to understand in an educational setting.

\section{Conclusions}

The results from this study show that students discuss the meaning in relation to the competency framework, and this may be of concern in a more general sense. It shows that meaning attached to certain competencies or behaviors is not always evident, leading to differences or disagreement in interpretation, and this may be the case for more competencies and on a broader scale. Similar lack of alignment between what the 
professional field intends and how this aligns with actual learning in an educational setting is seen in other professional fields. Examples can be found in relation to medical and pharmacy education where the need for better communication between educators and the professional field is necessary to improve alignment (Paradis, Zhao, Kellar, \& Thompson, 2018; Frenk, Chen, Bhutta, Cohen, Crisp, Evans, ... \& Kistnasamy, 2010).

This spurs the need for constant communication and updating of competency frameworks and their associated behaviors to ensure their meaning and interpretations are up-to-date, clear, and similar between all stakeholders. In the context of social constructivist view on competency-based education, whereby students construe their learning outcomes based on a competency framework, it becomes especially important to also involve students as stakeholders in this process of communication about the intended learning outcomes to align with the work field. Besides, as teachers are facilitators and guide students through the learning process, they need to stay up-to-date with meaning and interpretation of competency frameworks to ensure that, with the contents being clear, related meaningfulness can be experienced among students.

Besides results related to interpretation and attached meaningfulness, a further notable result is that meaningfulness was attached to a competency that was novel to students. This was the case with the competency self-reflection. It was new and never offered in the regular IB program, and, therefore, students regarded it as meaningful.

González-Cutre, Sicilia, Sierra, Ferriz, \& Hagger (2016) define novelty as "the need to experience something not previously experienced or deviates from everyday routine" ( $p$. 159). They propose that novelty is a fourth basic psychological need to drive motivation in addition to the current three in the self-determination theory: competence, relatedness, and autonomy (González-Cutre et al., 2016). If meaningfulness is related to having a novel experience, or experiencing something novel is considered as one of the basic motivation needs, then this will make adding novel competencies relevant.

In addition to self-reflection being novel and therefore meaningful, the meaningfulness of the self-reflection domain was further enhanced as students perceived it as a binding and omnipresent component of the HP. Self-reflection was used as a powerful means to reflect on the other competencies of the HTIBP competency profile, making it relevant and meaningful to students when working with the HTIBP profile. Self-reflection stimulates critical thinking, which is an important skill that is needed for continuous learning and improvement. The ability to reflect is regarded as an important skill for life-long learning and an important $21^{\text {st }}$ century skill (Helyer, 2015).

The results of this study give some initial insights related to student perceptions on the relevance and meaningfulness of the competencies and if this aligns with the professional field. In students' perspectives meaningfulness of competencies is connected to clarity and novelty of them, and this may help educators to better facilitate students. By better facilitating students, this may contribute to improving alignment with the professional field. 


\section{Limitations}

As data collection was restricted to one educational institution, transferability of the results is limited. Data collection and analysis in multiple IB HPs would improve transferability and may be considered for future research.

The responses of the interviewees may have contained acquiescence bias. However, ensuring that the interviewer was not an HP faculty member may have minimized this. The anonymity associated with the survey may have encouraged participants to be more critical.

In the present study, we have not interviewed faculty to obtain their perspectives on the HTIBP as it was beyond the scope of this study. As faculty may transmit their opinions to students through coursework and interactions, this would be a valuable area for further research.

\section{Practical implications}

Despite the aforementioned limitations, the research results may inspire some suggestions as to how to improve alignment between education and the professional field.

To help students experience the competencies as relevant and meaningful, clarity of them can be enhanced. Plenary sessions or webinars prior to working with the HTIBP profile to explicate how the behaviors to the domains are intended by the professional field could be organized. Additionally, involving senior students who can also communicate about meaning or interpretation of competencies to students will be beneficial. Furthermore, frequently checking meaning and relevance with the professional field can help with students seeing them as meaningful too.

In addition, calibration between stakeholders may also lead to novel additions to the competency framework, currently perhaps missing. Our research suggests that experiencing novel competencies is related to experiencing meaningfulness, making novel additions to the competency framework important. More flexible competency frameworks, allowing for adaptations and additions, would be beneficial. Mutual sharing of perspectives between all stakeholders can contribute to improving alignment. This should be an iterative process to check the current relevance of the competency framework with the changing demands of the professional field in the fast changing world.

Besides clarity and novel competencies being associated with experiencing relevance and meaningfulness, also educators, in their role as facilitators and mentors, can specifically address relevance and meaningfulness of competencies with students prior to working with them. Thereby, it becomes relevant to ensure that educators have sufficient and relevant business related experience to be able to do this. In part, this may also mean having to allocate extra funding for additional training or business exposure for educators. Besides educators, involving business professionals themselves to enhance relevance and meaningfulness for students is important. Business professionals can be invited as guests speakers to communicate relevance and meaningfulness of competencies. In addition, organizing dialogues between alumni and students can be another way of helping students to perceive competencies as relevant and meaningful. 
Our research also shows that self-reflecting was regarded as a powerful means of managing students' own learning, and, while it was one of the domains of the HTIBP, students applied self-reflecting to all the HTIBP domains. If self-reflection is a means for improvement and self-improvement, it could receive focus in regular IB programs, currently neglected (Longmore, Grant, \& Golnaraghi, 2018).

\section{References}

Abraham, S. E., \& Karns, L. A. (2009). Do business schools value the competencies that businesses value? Journal of Education for Business, 84(6), 350-356. doi:

10.3200/JOEB.84.6.350-356

Allen, J., Ramaekers, G., \& van der Velden, R. (2005). Measuring competencies of higher education graduates. New Directions for Institutional Research, 126, 49-59. doi:

10.1002/ir.147

Attali, M. O., \& Yemini, M. (2017). Initiating consensus: Stakeholders define entrepreneurship in education. Educational review, 69(2), 140-157.

doi:10.1080/00131911.2016.1153457

Banis-den Hertog, J. H. (2016). X-factor for innovation: Identifying future excellent professionals. Dissertation. The Netherlands: University of Twente. doi:

10.3990/1.9789036542531

Beck, C., \& Kosnik, C. (2006). Innovations in teacher education: A social constructivist approach. Albany: State University of New York Press.

Beechler, S. \& Woodward, I.C. (2009). The global war for talent. Journal of International Management, 15(3), 273-285. doi:10.1016/j.intman.2009.01.002

Biemans, H., Nieuwenhuis, L., Poell, R., Mulder, M., \& Wesselink, R. (2004). Competencebased VET in the Netherlands: Background and pitfalls. Journal of Vocational Education and Training, 56(4), 523-538. doi: 10.1080/13636820400200268

Boyatzis, R. E. (2008). Competencies in the 21st century. Journal of Management Development, 27(1), 5-12. doi: 10.1108/02621710810840730

Bruner, J. S. (1990). Acts of meaning. Harvard, Cambridge, MA: University Press.

Chyung, S. Y., Stepich, D., \& Cox, D. (2006). Building a competency-based curriculum architecture to educate 21st-century business practitioners. Journal of Education for Business, 81(6), 307-314. doi: 10.3200/JOEB.81.6.307-314

De Bruijn, E., \& Leeman, Y. (2011). Authentic and self-directed learning in vocational education: Challenges to vocational educators. Teaching and Teacher Education, 27(4), 694702. 
De Vos, A., De Hauw, S., \& Van der Heijden, B. I. (2011). Competency development and career success: The mediating role of employability. Journal of vocational behavior, 79(2), 438-447.

Dragoo, A., \& Barrows, R. (2016). Implementing competency-based business curricula in higher education. Journal of Education for Business, 91(7), 374-379. doi:

10.1080/08832323.2016.1237932

Farndale, E., Scullion, H. \& Sparrow, P. (2010). The role of the corporate HR function in global talent management. Journal of World Business, 45(2), 161-168. doi:

10.1016/j.jwb.2009.09.012

Florida, R. (2006). The flight of the creative class: The new global competition for talent. Liberal Education, 92(3), 22-29. doi: 10.2307/20031721

Frenk, J., Chen, L., Bhutta, Z. A., Cohen, J., Crisp, N., Evans, T., ... \& Kistnasamy, B. (2010). Health professionals for a new century: transforming education to strengthen health systems in an interdependent world. The Lancet, 376(9756), 1923-1958.

González-Cutre, D., Sicilia, Á., Sierra, A. C., Ferriz, R., \& Hagger, M. S. (2016). Understanding the need for novelty from the perspective of self-determination theory. Personality and Individual Differences, 102, 159-169.

Helyer, R. (2015). Learning through reflection: the critical role of reflection in work-based learning (WBL). Journal of Work-Applied Management, 7(1), 15-27. doi.org/10.1108/JWAM10-2015-003

Hennink, M., Hutter, I., \& Bailey, A. (2010). Qualitative research methods. London, UK: Sage Publications Limited.

Jackson, D. 2009. Profiling industry-relevant management graduate competencies: The need for a fresh approach. International Journal of Management Education, 8(1): 85-98. doi: 10.3794/ijme.81.281

Jackson, D. (2013). Business graduate employability-where are we going wrong? Higher Education Research \& Development, 32(5), 776-790.

Jackson, D. (2014). Testing a model of undergraduate competence in employability skills and its implications for stakeholders. Journal of Education and Work, 27(2), 220-242. doi: $10.1080 / 13639080.2012 .718750$

Jang, H., Reeve, J., \& Deci, E. L. (2010). Engaging students in learning activities: It is not autonomy support or structure but autonomy support and structure. Journal of educational psychology, 102(3), 588-600. doi.org/10.1037/a0019682. 
Johnson, D. (2001). What is innovation and entrepreneurship? Lessons for larger organisations. Industrial and commercial training, 33(4), 135-140.

Lawshe, C. H. (1975). A quantitative approach to content validity. Personnel Psychology, 28(4), 563-575.

Lewrick, M., Omar, M., Raeside, R., \& Sailer, K. (2011). Education for entrepreneurship and innovation: Management capabilities for sustainable growth and success. World Journal of Entrepreneurship, Management and Sustainable Development, 6(1/2), 1-18.

Longmore, A. L., Grant, G., \& Golnaraghi, G. (2018). Closing the 21st-Century Knowledge Gap: Reconceptualizing Teaching and Learning to Transform Business Education. Journal of Transformative Education, 16(3), 197-219.

Marvel, M. R., Davis, J. L., \& Sproul, C. R. (2016). Human capital and entrepreneurship research: A critical review and future directions. Entrepreneurship Theory and Practice, 40(3), 599-626.

McQuaid, Ronald W., \& Lindsay, Colin. 2005. The concept of employability. Urban Studies, 42(2): 197-219. doi: 10.1080/0042098042000316100

Moeller, A., Theiler, J., \& Wu, C. (2012). Goal setting and student achievement: A longitudinal study. The Modern Language Journal, 96, 153-169.

https://doi.org/10.1111/j.1540-4781.2011.01231.x.

Mouratidis, A., Vansteenkiste, M., Michou, A., \& Lens, W. (2013). Perceived structure and achievement goals as predictors of students' self-regulated learning and affect and the mediating role of competence need satisfaction. Learning and Individual differences, 23, 179-186. doi.org/10.1016/j.lindif.2012.09.001

Neck, H. M., \& Greene, P. G. (2011). Entrepreneurship education: known worlds and new frontiers. Journal of Small Business Management, 49(1), 55-70.

Nodine, T. R. (2016). How did we get here? A brief history of competency-based higher education in the United States. The Journal of Competency-Based Education, 1(1), 5-11.

Osmani, M., Weerakkody, V., Hindi, N. M., Al-Esmail, R., Eldabi, T., Kapoor, K., \& Irani, Z., (2015). Identifying the trends and impact of graduate attributes on employability: a literature review. Tertiary Education and Management, 21(4), 367-379.

Paradis, E., Zhao, R., Kellar, J., \& Thompson, A. (2018). How are competency frameworks perceived and taught? An exploratory study in the context of pharmacy education. Perspectives on medical education, 1-7.

Reeve, J. (2009). Why teachers adopt a controlling motivating style toward students and how they can become more autonomy supportive. Educational Psychologist, 44(3), 159-175. 
Reis, S. M., \& Renzulli, J. S. (2010). Is there still a need for gifted education? An examination of current research. Learning and Individual Differences, 20(4), 308-317.

Ryan, R. M., \& Deci, E. L. (2000). Self-determination theory and the facilitation of intrinsic motivation, social development, and well-being. American psychologist, 55(1), 68.

Scager, K., Akkerman, S. F., Keesen, F., Mainhard, M. T., Pilot, A., \& Wubbels, T. (2012). Do honors students have more potential for excellence in their professional lives? Higher Education, 64(1), 19-39.

Scager, K., Akkerman, S. F., Pilot, A., \& Wubbels, T. (2014). Challenging high-ability students. Studies in Higher Education, 39(4), 659-679.

Schell, J. W. (2000). Think about authentic learning and then authentic assessment. In R.L. Custer (Ed.), Using authentic assessment in vocational education, (pp. 7-18), Information series no. 381, Columbus, OH. ERIC Clearinghouse on Adult, Career and Vocational Education.

Silzer, R., \& Church, A.H. (2009). The pearls and perils of identifying potential. Industrial and Organizational Psychology, 2(4), 377-412. doi:10.1111/j.1754-9434.2009.01163.x

Shore, B. M., and Kanevsky, L. (1993). Thinking processes: Being and becoming gifted. In: Heller, K. A., Moenks, F. J., and Passow, A. H. (Eds.), International handbook of research and development of giftedness and talent, (pp. 133-147). Oxford: Pergamon.

Tarique, I. and Schuler, R. S. (2010). Global talent management: Literature review, integrative framework, and suggestions for further research. Journal of World Business, (45)2, 122-133.

Tran, T. T. (2015). Is graduate employability the 'whole-of-higher-education-issue'? Journal of Education and Work, 28(3), 207-227. doi: 10.1080/13639080.2014.900167

Tymon, A. (2013). The student perspective on employability. Studies in higher education, 38(6), 841-856.

van Heugten, P., Heijne-Penninga, M., Paans, W., \& Wolfensberger, M. (2016).

Characteristics of highly talented international business professionals defined: Qualitative study among international business professionals. European Journal of Training and Development, 40(2), 58-73. doi: 10.1108/EJTD-04-2015-0032

Van Merriënboer, J.J.G., van der Klink, M.R. \& Hendriks, M. (2002). Competenties: van complicaties tot compromis. Over schuifjes en begrenzers. Den Haag: Onderwijsraad.

Vansteenkiste, M., Lens, W., \& Deci, E. L. (2006). Intrinsic versus extrinsic goal contents in self-determination theory: Another look at the quality of academic motivation. Educational psychologist, 41(1), 19-31. 
Veeraraghavan, V. (2009). Entrepreneurship and innovation. Asia Pacific Business Review, 5(1), 14-20.

Wolfensberger, M.V.C., \& Offringa, G.J. (2012). Qualities Honors Students Look for in Faculty and Courses revisited. Journal of the National Honors Council, Fall/Winter, 171-182

Wolfensberger, M. V. C. (2015). Talent development in European higher education: Honors programs in the Benelux, Nordic and German-speaking countries. London: Springer. doi: 10.1007/978-3-319-12919-8

Zhao, F. (2005). Exploring the synergy between entrepreneurship and innovation. International Journal of Entrepreneurial Behavior \& Research, 11(1), 25-41. 
Appendix A. Interview guide

\begin{tabular}{|c|c|}
\hline Area & Questions \\
\hline Exploring survey results & $\begin{array}{l}\text { 1. In a student survey, the behavior 'showing } \\
\text { entrepreneurship' is, on average, not perceived as } \\
\text { essential to talent (and in the professional field it is). } \\
\text { What is your opinion on this? } \\
\text { 2. In a student survey, the behavior 'improving ideas } \\
\text { from others' is, on average, not perceived as essential } \\
\text { to talent (and in the professional field it is). What is } \\
\text { your opinion on this? } \\
\text { 3. In a student survey, the domain "Innovation" is, } \\
\text { perceived as essential to talent. What is your opinion } \\
\text { on this? }\end{array}$ \\
\hline $\begin{array}{l}\text { Students' perspectives on the } \\
\text { meaningfulness and } \\
\text { relevance of the HTIBP } \\
\text { profile }\end{array}$ & $\begin{array}{l}\text { 4. What domains and or behaviors of the HTIBP } \\
\text { profile are the most meaningful/ significant to you? } \\
\text { 4a. Could you explain why? } \\
\text { 5. What domains and or behaviors of the HTIBP } \\
\text { profile are the least meaningful/ significant to you? } \\
\text { 5a. Could you explain why? } \\
\text { 6. Are there any domains or behaviors that you have } \\
\text { not used? }\end{array}$ \\
\hline Assessment & $\begin{array}{l}\text { 7. How have the competencies of the HTIBP profile } \\
\text { been assessed? } \\
\text { 7a. Have you perceived the assessments as } \\
\text { meaningful? } \\
\text { 7b. Could you explain why? }\end{array}$ \\
\hline $\begin{array}{l}\text { Students' perspectives on } \\
\text { working with the HTIBP } \\
\text { profile }\end{array}$ & $\begin{array}{l}\text { 8. How did you perceive working with the HTIBP } \\
\text { profile? } \\
\text { 9. Are there any domains or behaviors that are } \\
\text { missing from the HTIB profile? }\end{array}$ \\
\hline
\end{tabular}

